\title{
Decontamination of Toxic Volatile Organic Compounds in Charcoal Processed from Erythrophleum guineense (Sassy Wood)
}

\author{
John Stephen Gushit*, Ester Habila \\ Department of Science Laboratory Technology, Faculty of Natural Sciences, University of Jos, Jos, Plateau State, Nigeria \\ Email address: \\ gushitj@unijos.edu.ng (J. S. Gushit), esterhabila84@gmail.com (E. Habila) \\ ${ }^{*}$ Corresponding author \\ To cite this article: \\ John Stephen Gushit, Ester Habila. Decontamination of Toxic Volatile Organic Compounds in Charcoal Processed from Erythrophleum \\ guineense (Sassy Wood). Journal of Chemical, Environmental and Biological Engineering. Vol. 4, No. 2, 2020, pp. 60-65. \\ doi: $10.11648 /$ j.jcebe. 20200402.15
}

Received: June 30, 2020; Accepted: July 17, 2020; Published: August 4, 2020

\begin{abstract}
The work aimed at decontaminating potentially toxic compounds found in the charcoal sample, started with collecting the sample of charcoal processed from Erythrophleum guineense (Sassy wood) established in an earlier work to be emitting toxic compounds. The sample was subjected to combustion in a chamber and the volatiles organic compounds (VOCs), formaldehyde (HCHO) and other air quality parameters detected from the hot smoke emitted using the Air Pollutant Detector (Air Master). The VOCs and HCHO average concentration of $2.98 \mathrm{mg} / \mathrm{m}^{3}$ and $1.27 \mathrm{mg} / \mathrm{m}^{3}$ respectively were detected in the sample, giving indication of extremely high concentration beyond standard permissible limits. The decontaminants which includes; $\mathrm{CaO}, \mathrm{NaCl}, \mathrm{KOH}, \mathrm{NaCl} / \mathrm{CaO}(1: 1)$ and $\mathrm{Al}_{2} \mathrm{O}_{3}$ were prepared by dissolving pulverized portion of each in a small amount of distilled water and diluted with purified dual-purpose kerosene (DPK), after which each solution was uniformly sprayed on the pre-weighed charcoal in the combustion chamber. On applying the prepared decontaminants: $\mathrm{CaO}, \mathrm{NaCl}, \mathrm{KOH}, \mathrm{NaCl} / \mathrm{CaO}$ and $\mathrm{Al}_{2} \mathrm{O}_{3}$ on the charcoal, the VOCs concentration of $0.32 \mathrm{mg} / \mathrm{m}^{3}, 0.60 \mathrm{mg} / \mathrm{m}^{3}, 0.61 \mathrm{mg} / \mathrm{m}^{3}, 1.11 \mathrm{mg} / \mathrm{m}^{3}$ and $2.88 \mathrm{mg} / \mathrm{m}^{3}$ respectively were detected, which showed significant reduction in the concentration of the VOCs emitted that is far below the WHO limits for short term exposure of $0.1 \mathrm{mg} / \mathrm{m}^{3}$, indicating that using the decontaminants is required if such charcoals must continue to be used. The VOCs were characterized in all the samples after they were adsorbed, desorbed, extracted, purified, concentrated and finally detected using the Gas chromatography Mass Spectrometry (GC-MS). The VOCs detected are; Octadecanoic, n-hexadecenoic acid, levomenthol acid and cyclobutanol acid widely reported to be toxic. Therefore, the work recommends that charcoal fires should not be ignited and used in enclosures, and appropriate Government regulatory agencies should create awareness on the need to avoid the use of Erythrophleum guineense (sassy wood) charcoal. If it must be used, decontaminant like CaO prepared from this work should be used since it is a cheap and accessible waste material found in auto mechanic garages indiscriminately discarded by gas welders.
\end{abstract}

Keywords: Decontamination, Volatile Organic Compounds (VOCs), Formaldehyde (HCHO)

\section{Introduction}

Charcoal is the dark-grey residue consisting of carbon and any remaining of heating wood and other substances in the absences of oxygen, often obtained from plant-based materials through the process of pyrolysis [1]. It is an excellent domestic fuel and can be made from virtually any organic material like wood, coconut shells, rice husks and bones. It also contains little percentage of ash being the inorganic constituent.
Charcoal though an old source of energy is still being used for cooking both in rural and urban centers. It was reported [2] that half of the world's population use biomass fuel for cooking and that in 1992, twenty-four (24) million tons of charcoal were consumed worldwide, with developing countries accounting for most of the consumption, with Africa alone accounted for $50 \%$. The lack of readily available, 
accessible or affordable alternative fuels, especially in low-income countries, contributes to a dependence on charcoal [3]. The cry for alternative energy sources due to the effects of global warning has put charcoal in the forefront of the global market [4]. The use of solid fuels (biomass and coal) for cooking tense to contribute to elevated concentrations of hazardous pollutants [5]. Indoor air pollutant emanating from burning solid fuels (wood, charcoal, animal dung, coal and crop waste) for cooking and home heating remains a major environmental and public health challenge in developing countries [6]. Charcoal that is not properly burned in the presence of sufficient carbon dioxide end up producing products of incomplete combustion-primarily carbon monoxide, benzene, butadiene, formaldehyde, poly aromatic hydrocarbons and many other compounds posing health hazards [7], which symptoms of exposure to can include headache, dizziness, nausea, impaired psychomotor function (and also some abnormal behavioral function), loss of balance, fatigue and respiratory symptoms. As the concentration increases, these symptoms intensifies [8]. The ability of organic chemicals to cause health effects varies greatly from those that are highly toxic, to those with no known health effects. Some of these compounds are; VOCs, such as styrene and limonene, which can react with nitrogen oxides or with ozone to produce new oxidation products and secondary aerosols, which can cause sensory irritation symptoms [9]. Since many people spend much of their time indoors, long-term exposure to VOCs in the indoor environment can contribute to sick building syndrome [10]. Many of these compounds are known to cause cancer in animals; some are suspected of causing, or are known to cause, cancer in humans [11]. Emission of toxic chemical substances are spotted as one of the major challenges of using some charcoal products which could apart from compromising indoor air quality could even cause death to human other non-target living beings. For instance, it is reported that there are public health cases linked to use of charcoal where about $20 \%$ deaths of children $<5$ years of age as a result of exposure to charcoal heating in some confined environments [12]. There are both health and environmental issues involved with the use of charcoal as a fuel. The health issues that arise from using charcoal are the same problems that arise from the use of other solid fuels. These health issues, primarily due to the smoke emitted when the charcoal is burned, includes an increased number of cases of pneumonia, stroke, heart disease, and lung cancer. Overall, the World Health Organization (WHO) estimates that there are 4 million deaths per year that are partially caused by the use of solid fuels, including charcoal [13]. On the other hand, most of the pollutants trigger global warming and formation of the secondary compounds which are more complex in environment. VOCs in the environment can be detected using special detectors containing special sensors for various chemical. In many cases, VOCs are detectable by the human nose, and odor wheels are sometimes developed to help humans classify complex odors of wine, coffee, and even paper [14]. There are electronic devices that can detect the concentrations in part per million despite the non-selectivity. Others can predict with reasonable accuracy the molecular structure of the VOCs in the open environment or enclosed atmospheres [15] and could be used as accurate monitors of the Chemical Fingerprint and further as health monitoring devices. Solid-phase microextraction (SPME) techniques are used to collect VOCs at low concentrations for analysis [16]. A lower explosion limit (LEL) detector such as a flame ionization detector (FID) may be used to measure the total concentration of VOCs, though it cannot differentiate between or identify the particular species of VOC. Similarly, a photoionization detector (PID) may also be used, though PIDs are less accurate. Direct injection mass spectrometry techniques are frequently utilized for the rapid detection and accurate quantification of VOCs [17].

Treatment methods of VOCs are generally classified into two categories. One is by trapping these compounds and removing them from the system with the possible utilization of valuable compound referred to as nondestructive methods, while the others involve converting them chemically into harmless compounds called destructive methods [18]. However, the type and concentration of VOCS determine the choice of treatment method. Measurement of VOCs from the indoor air is done with sorption tubes (Tenax for VOCs and SVOCs) or (DNPH-cartridges for carbonyl-compounds) or air detector. The VOCs adsorb on these materials and are afterwards desorbed either thermally (Tenax) or by elution (DNPH) and then analyzed by GC-MS /FID or HPLC. Furthermore, VOCs emitting products used indoors, e.g. building products and furniture, are investigated in emission test chambers under controlled climatic conditions. For quality control of these measurements round robin tests are carried out, therefore reproducibly emitting reference materials are ideally required. The physio-chemical techniques also involves the treatment of VOCs through oxidation by thermal, internal combustion engine (ICE) and ultraviolet oxidation (UV). The by-products of this process are; $\mathrm{CO}_{2}, \mathrm{H}_{2} \mathrm{O}$ and $\mathrm{HCl}$. Regarding the $\mathrm{UV}$ (catalytic) oxidation method, a catalyst and oxidizer is used to speed up the oxidation process [19], and the removal takes place at the surface of the catalyst by adsorption including organic compounds and oxygen reactions. From a VOC recovery view point, adsorption, condensation, absorption, and membrane separation are commonly used at the industrial scale.

The traditional technologies for VOCs removal include adsorption, membrane separation, liquid absorption, and catalytic combustion [20]. Many of these techniques have been widely applied in industries or commercial sectors, but few are being further developed or optimized [21, 22]. Adsorption is the most traditional method for removal of VOCs. Activated carbon, molecular sieve and silica gel are porous materials with a large surface area medium for physical and chemical adsorption. The common absorbents contain inorganic salts (e.g., ammonium and sulfurous) and are composed with amine groups such as urea and its derivatives, hydrazine, and amino-containing polymers [23, 24]. Catalytic oxidation technology with thermal treatment is another effective method for VOCs removal. Formaldehyde reacts with oxygen $\left(\mathrm{O}_{2}\right)$ over noble metals producing $\mathrm{CO}_{2}$ and $\mathrm{H}_{2} \mathrm{O}$ vapor [25]. In Plasma catalytic method, the molecules, particles, atoms and free radicals are excited to have high chemical activities for the 
decomposition of VOCs, but the reactions are difficult to control in normal conditions and the reaction rates are usually slow [26]. This work is aimed at decontaminating toxic volatile organic compounds emitted from in charcoal sample using readily available decontaminants.

\section{Materials and Methods}

\subsection{Study Area Science}

The samples used for this study was collected at Jengre, Bassa LGA and Maza, Jos North LGA, Plateau State, North Central Nigeria. Jos North is located in the North-West of the State, which is situated on latitude $7^{\circ}$ and $11^{\circ} \mathrm{N}$ and longitude $7^{\circ}$ and $25^{\circ} \mathrm{E}$ and at an average altitude of about $1200 \mathrm{~m}$ above sea level; with a population of about 873,943 at the Census, 2006. Bassa is a Local Government Area in the northern part of Plateau State, Nigeria, bordering Kaduna and Bauchi States. It is located longitude $9^{\circ} 56^{\prime} 00^{\prime \prime} \mathrm{N}$ and latitude $8^{\circ} 44^{\prime} 00^{\prime \prime E}$ [27].

\subsection{Materials and Reagents}

The reagents and material used during the analysis include; purified dual purpose kerosene (DPK), $\mathrm{NaCl}, \mathrm{CaO}, \mathrm{Al}_{2} \mathrm{O}_{3}$, $\mathrm{KOH}, \mathrm{NaCl}$, distilled water, n-hexane, silica gel, ammonia, Dichloromethane, sample shakers, combustion chamber, measuring cylinder, sampling bottles, pipes, suction pump, watch, mobile Air pollutant detector (Air Master) and Gas Chromatography.

\subsection{Sample Collection and Preparation of Decontaminants}

The major samples used for this research is charcoal processed from Erythrophleum guineense (Sassy wood), a tree plant locally referred to as 'Gwaska' in Hausa language. They were collected at Jengre, Bassa LGA and Maza, Jos North LGA, Plateau state, Nigeria. The decontaminants which includes; $\mathrm{NaCl}, \mathrm{CaO}, \mathrm{Al}_{2} \mathrm{O}_{3}$ and $\mathrm{KOH}$ were collected within that research environment and prepared in the Chemical Laboratory of University of Jos, Nigeria. Each of the salts used as decontaminant were dried using the oven maintained $105^{\circ} \mathrm{C}$ for 1 hour, thereafter pulverized to a mesh size of $0.2 \mathrm{~mm}$. They were dissolved in small amount of deionized water after which they were diluted in purified dual purpose kerosene (DPK), and the solution homogenized and sprayed on the pre-weighed charcoal sample in a combustion chamber, before igniting it. A pre-calibrated air pollutant detector (Air Master) was used to detect air quality parameters such as: $\mathrm{VOCs}, \mathrm{CO}_{2}, \mathrm{HCHO}$, Temp, $\mathrm{PM}_{10}, \mathrm{PM}_{2.5}$ and Relative Humidity ( $\mathrm{RH}$ ) from the smoked emitted through the chimney of the combustion chamber.

\subsection{Characterization of VOCs}

To characterize the VOCs gases emitted, a sorption unit was set to trap these chemical substances over activated carbon packed in test tube open from both ends and cloaked with cotton wool. This was eluded on addition of small amount of ammonia and rinsed with dichloromethane (DCM). These were collected in glass sample bottles and DCM added (solvent used for desorption), after which the sample bottle was placed on a mechanical shaker for proper extraction. A micro purification columns packed with silica gel, was set up to clean the extracts. They were concentrated to $2 \mathrm{ml}$ before analyzing using Gas chromatography coupled with mass spectrometric detection (GC-MS). The model of the GC-MS used is Agilent GC 7890B, MSD 5977A, Agilent Technologies, USA. The GC column was eluded with an initial oven temperature of $30^{\circ} \mathrm{C}$ increased to $60^{\circ} \mathrm{C}$ after holding for $3 \mathrm{~min}$ at a rate of $3^{\circ} \mathrm{C} \mathrm{min}^{-1}$ and finally to $240^{\circ} \mathrm{C}$ at the rate of $45^{\circ} \mathrm{C} \mathrm{min}^{-1}$. Helium was used as carrier gas at a constant flow rate of $40 \mathrm{ml} \mathrm{min}^{-1}$.

\section{Results and Discussions}

This study reveals that Erythrophleum guineense (Sassy wood) locally known as 'gwaska' is used for medicinal purposes. In addition, the trunk of the plant is known to be locally used to produce charcoal across the nation. But only few have the knowledge that the plant is toxic and post a great deal of threat to lives. However, because the local charcoal making is a stable means of livelihood for the communities where this is used, they produce the charcoal from this plant and sell it to the city dwellers who know nothing about the sources of the charcoal. It is when they are using it that they end up being victim of exposure from the charcoal product that emitted the toxic chemical in form of VOCs. Most of the chemicals emitted are VOCs of interest owning to toxicity linked to them [28]. Table 1 provides the quantity of charcoal, substances (samples) and dual purpose kerosene (DPK) used to prepare the decontaminants.

Table 1. Quantity of charcoal and decontaminating substances used.

\begin{tabular}{|c|c|c|c|c|c|}
\hline \multirow{2}{*}{$\mathbf{S} / \mathbf{N}$} & \multirow{2}{*}{ Samples } & Sample & Wt. of Salt & DPK & Wt. of Charcoal \\
\hline & & Code & (kg) & $(\mathrm{ml})$ & $(\mathrm{Kg})$ \\
\hline 1 & Control & A & - & 80 & 0.520 \\
\hline 2 & $\mathrm{CaO}$ & $\mathrm{B}$ & 20 & 80 & 0.630 \\
\hline 3 & $\mathrm{NaCl}$ & $\mathrm{C}$ & 20 & 80 & 0.635 \\
\hline 4 & $\mathrm{CaO}+\mathrm{NaCl}$ & $\mathrm{D}$ & 20 & 80 & 0.631 \\
\hline 5 & $\mathrm{Al}_{2} \mathrm{O}_{3}$ & E & 20 & 80 & 0.630 \\
\hline 6 & $\mathrm{KOH}$ & $\mathrm{F}$ & 20 & 80 & 0.634 \\
\hline
\end{tabular}

\subsection{Detection Analysis}

Table 2 shows seven (7) different parameters detected on the charcoal sample using air pollutant detector (Air master) which were; VOCs, $\mathrm{HCHO}, \mathrm{CO}_{2}, \mathrm{PM}_{10}, \mathrm{PM}_{2.5}$, and RH. After they were decontaminated with the following salts; $\mathrm{CaO}$, $\mathrm{NaCl}, \mathrm{KOH}, \mathrm{Al}_{2} \mathrm{O}_{3}$ and $\mathrm{NaCl}+\mathrm{CaO}$ mixture. The initial concentration of VOC in the 'Gwaska' charcoal was 2.98 $\mathrm{mg} / \mathrm{m}^{3}$ (Table 2), which is above environmentally acceptable background range of 0.60 to $1.00 \mathrm{mg} / \mathrm{m}^{3}$ for TVOC set for Indoor Air Quality (IAQ). 
Table 2. Air Pollutant (Air Master) Detector Analysis of the Charcoal Samples.

\begin{tabular}{lllllll}
\hline VOC & $\mathbf{C O}_{2}$ & HCHO & Temp & $\mathbf{P M}_{\mathbf{1 0}}$ & $\mathbf{P M}_{2.5}$ & RH \\
\hline$\left(\mathbf{m g} / \mathbf{m}^{3}\right)$ & $\left(\mathbf{m g} / \mathbf{m}^{\mathbf{3}}\right)$ & $\left(\mathbf{m g} / \mathbf{m}^{3}\right)$ & $\left({ }^{\circ} \mathbf{C}\right)$ & $\left(\boldsymbol{\mu g} / \mathbf{m}^{3}\right)$ & $\left(\boldsymbol{\mu g} / \mathbf{m}^{3}\right)$ & $\mathbf{( \% )}$ \\
\hline 2.98 & 2520 & 1.27 & 35.7 & 35 & 37 & 47.4 \\
0.32 & 2340 & 1.24 & 33.0 & 807 & 493 & 45.0 \\
0.6 & 210 & 0.02 & 32.0 & 571 & 482 & 42.4 \\
1.11 & 2260 & 0.07 & 32.8 & 401 & 393 & 48.9 \\
2.88 & 410 & 0 & 27.9 & 18 & 16 & 45.1 \\
0.61 & 410 & 0 & 28.1 & 19 & 17 & 45.2 \\
\hline
\end{tabular}

\subsection{Volatile Organic Compounds (VOCs) and Formaldehyde ( $\mathrm{HCHO})$}

Table 2 gives the indication that on using the decontaminants; $\mathrm{CaO}, \mathrm{NaCl}, \mathrm{KOH}, \mathrm{NaCl} / \mathrm{CaO}$ and $\mathrm{Al}_{2} \mathrm{O}_{3}$, the concentration of $0.32 \mathrm{mg} / \mathrm{m}^{3}, \quad 0.60 \mathrm{mg} / \mathrm{m}^{3}, \quad 0.61 \mathrm{mg} / \mathrm{m}^{3}, \quad 1.11 \mathrm{mg} / \mathrm{m}^{3}$ and $2.88 \mathrm{mg} / \mathrm{m}^{3}$ respectively were detected. This shows there was significant reduction in the VOCs concentration after using the decontaminants. Similarly, HCHO which is also a type of VOC have a concentration $2.73 \mathrm{mg} / \mathrm{m}^{3}$ detected from the charcoal samples. But after the decontamination process using the different decontaminants, there was a significantly reduction in the concentration of the $\mathrm{HCHO}$. Where $\mathrm{KOH}$ and $\mathrm{Al}_{2} \mathrm{O}_{3}$ were used as decontaminants, $100 \%$ reduction of the $\mathrm{HCHO}$ concentration was recorded in both samples. While the least decontamination was recorded $\left(1.24 \mathrm{mg} / \mathrm{m}^{3}\right)$ when $\mathrm{CaO}$ was used. On the other hand, $\mathrm{NaCl}$ and $\mathrm{NaCl} / \mathrm{CaO}(50 \%$ w/w) were able to significantly reduce the $\mathrm{HCHO}$ leaving only $0.02 \mathrm{mg} / \mathrm{m}^{3}$ and $0.07 \mathrm{mg} / \mathrm{m}^{3}$ respectively in the samples after using these decontaminants. Comparing with WHO standard for short term guideline of $0.1 \mathrm{mg} / \mathrm{m}^{3}$ for HCHO [29]. This indicates that using the decontaminants are safe alternatives.

\subsection{Detection Analysis}

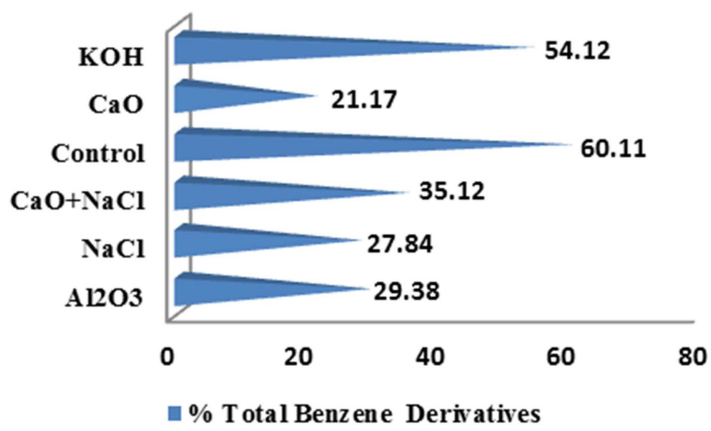

Figure 1. Trends of decontamination of benzene and its derivatives.

Figure 1 indicate the percentage occurrence of one of the families of the stable volatile organic compounds (VOCs), benzene and its derivatives detected in the charcoal sample before the decontamination (control), climaxing to an average $60.11 \%$. On applying the decontaminants, this was observed to reduce to $54.12 \%, 21.17 \%, 35.12 \%, 27.84 \%, 29.38 \%$ and for $\mathrm{KOH}, \mathrm{CaO}, \mathrm{CaO}+\mathrm{NaCl}, \mathrm{NaCl}$ and $\mathrm{Al}_{2} \mathrm{O}_{3}$ respectively. The trend in terms of strength of decontamination is $\mathrm{CaO}>\mathrm{NaCl}>\mathrm{Al}_{2} \mathrm{O}_{3}>\mathrm{CaO}+\mathrm{NaCl}>\mathrm{KOH}$, which clearly indicate that $\mathrm{CaO}$ and $\mathrm{NaCl}$ are able to decontaminate the TVOCs more than other decontaminants prepared. This justifies why the indigenous communities uses $\mathrm{NaCl}$ to decontaminate charcoals that are known for emitting toxic compounds.

On the other hand, carbonyl derivatives present in the sample are; Octadecanoic, n-hexadecenoic acid, levomenthol acid and cyclobutanol acid. Although there was no particular trend observed in them with the use of the decontaminants, but they are widely known for toxicity in varying degrees [30]. Effect of exposure to such compounds has been linked to conjunctival irritation, nose and throat discomfort, headache, allergic skin reaction, dyspnea, declines in serum cholinesterase levels, nausea, emesis, epistaxis, fatigue and dizziness [11]. It becomes very necessary to find alternatives to decontaminating them. The chemistry of the chemicals (salts, oxides and bases) used in decontaminating the VOCs under this experimental conditions may not in the immediate run be clear, but will not be unconnected to the fact that some of these decontaminants acts as catalyst under varying condition of pressure and temperature in the combustion chamber resulting in converting heavy fractions of the VOCs to lighter fractions making it less toxic. For instance, [31] reported excellent activity for removal of $\mathrm{HCHO}$ was facilitated when pretreated pt- $\mathrm{Al}_{2} \mathrm{O}_{3}$ catalytic preparation was used. Similarly, $\mathrm{CaO}$ have been used as a significant part of a catalyst prepared that improved biodiesel production by other researchers [32]. Table salt $(\mathrm{NaCl})$ was also used as catalyst for oxidation of aromatic alcohols and amines to acids and amines [33], all these point to the fact that the chemistry of the decontaminants used in this work is more with their catalytic activities.

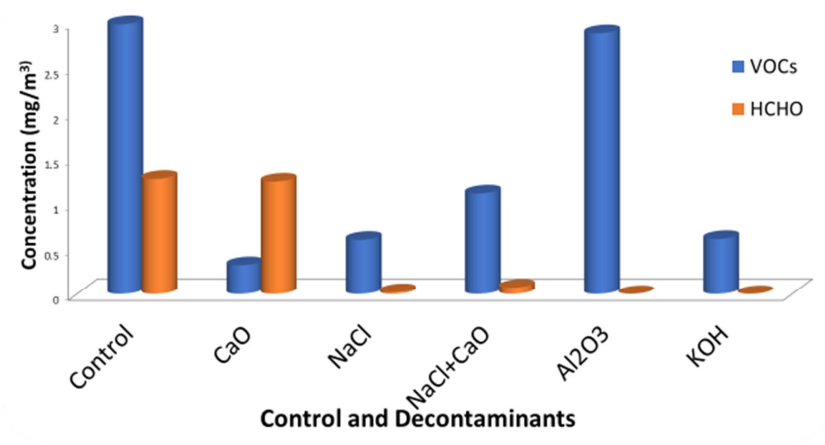

Figure 2. Concentration of VOCs and HCHO decontaminated.

\section{Conclusion}

This study has shown that the charcoal produced from Erythrophleum guineense (Sassy wood) locally known as 'Gwaska' emitted VOCs with average concentration of $2.98 \mathrm{mg} / \mathrm{m}^{3}$, is high when compared to permissible limits set for VOCs. A similar trend was observed with the $\mathrm{HCHO}$, with an average concentration of $2.73 \mathrm{mg} / \mathrm{m}^{3}$ detected. This result have answered the research question on the toxicity of charcoal, as many of the end users of these charcoal end up complaining of one health setbacks or other when exposed smoke emitted from it. With this revelation, charcoal from this plant should not be used for charcoal production, and where there is no alternative, decontaminants like $\mathrm{CaO}$ and $\mathrm{NaCl}$ 
prepared in this research can be used to decontaminate the charcoal before it is used.

\section{Acknowledgements}

The Nigerian Government Tertiary Education Trust Fund (TETFund) is acknowledged for supporting this research financially. The authors would like to thank the Management and Staff of University of Jos, Nigeria for allowing free access to Laboratory facilities needed for this work.

\section{References}

[1] Egbewole, Z. T. and O. Y. Ogunsanwo (2014). Assessment of Charcoal Production, Uses and its Calorific Value. Journal of Recent Advance in Agriculture, 2 (1), 157-167.

[2] Kammen, D. M., R. Bailis, and M. Ezzati, (2005). Mortality and greenhouse gas impacts of biomass and petroleum energy future in Africa. Science, 308 (5718), 98-103.

[3] Gesellschaftfur Internationale Zusammenarbeit [GIZ] (2014). Multiple-household fuel use: A balance choice between fuelwood, charcoal and LPG. Fschborn, Deutsche Gesellschaftfur Internationale Zusammenarbeit (GIZ). Germany.

[4] Anozie, A. N., A. R. Bakare, J. A., Sonibare, and T. O. Oyebisi, (2006). Evaluation of cooking energy cost, efficiency, impact on air pollution and policy in Nigeria. Energy, 32 (7), $1283-1292$.

[5] Oluwole, O., G. R. Ana, G. O. Arinola, T. Wiskel, A. G. Falusi, D. Huo, O. I. Olopade, and C. O. Olopade (2013). Effect of stove intervention on household air pollution and the respiratory health of women and children in rural Nigeria. Air Quality Atmosphere Health, 6 (3), 553-561.

[6] Ezeh, O. K., K. E. Agho, and A. P. Nicolas (2014). The effect of solid fuel use on childhood mortality in Nigeria: Evidence from the 2013 cross sectional household survey. Environmental Health, 13 (16), 113.

[7] Smith, K. R. (1993). Fuel combustion, air pollution exposure and health: The situation in developing countries. Annual Review of Energy and the Environment, 18 (1), 529-566.

[8] Chris, W. (2012). Carbon monoxide induced death and toxicity from charcoal. The Medical Journal of Australia, 197 (6), 349-350.

[9] Mendell, M. J. (2007). "Indoor residential chemical emissions as risk factors for respiratory and allergic effects in children: A review". Indoor Air, 17 (4), 259-77.

[10] Wang, S., H. M. Ang, and M. O. Tade (2007). Volatile organic compounds in indoor environment and photocatalytic oxidation: State of the art. Environment International, 33 (5), 694-705.

[11] Environmental Protection Agency [EPA] (2017). Volatile Organic Compounds' Impact on Indoor Air Quality. Indoor Air Quality (IAQ). Retrieved February $22 \quad 2020$ from https://www.epa.gov/indoor-air-quality-iaq/volatile-organic-co mpounds-impact-indoor-air-quality.

[12] Salvi, S. S. (2009). Chronic obstructive pulmonary disease in nonsmoker. Lancet, 374 (9691), 733-43.

[13] World Health Organization [WHO] (2012). Burden of disease from household air pollution (HAP) for 2012. Retrieved $\begin{array}{llll}\text { December } & 3, & 2019 & \text { from }\end{array}$ http://www.who.int/mediacentre/news/notes/2007/np20/en /index.html.

[14] Mazzyslaw, M., A. Pokorski, and D. C. Giulio (2015). Real time analysis of volatile organic compounds (VOCs). In centenarians. Respiratory Physiology \& Neurobiology, 209 (1), 47-51.

[15] Martínez, H., J. L. Davidson, C. A. B. Blyth, and C. R. Lowe (2010). "Holographic Detection of Hydrocarbon Gases and Other Volatile Organic Compounds". Langmuir. 26 (19).

[16] Lattuati, D. A., T. S. Bonnassies, and B. Lavédrine (2004). "Identification of volatile organic compounds emitted by a naturally aged book using solid-phase microextraction/gas chromatography/mass spectrometry". Journal of Chromatography Analysis, 1026 (1-2), 9-18.

[17] Biasioli, F., C. Yeretzian, T. D. Märk, J., Dewulf, and L. H. Van (2011). Direct-injection Mass Spectrometry adds the Time Dimension to VOC Analysis. Trends in Analytical Chemistry, 30 (7), 1003-1017.

[18] Berenjian, A., N. Chan, and H. J. Malmiri (2012). American journal of biochemistry and biotechnology. (8) No. 4 pp. 220-229.

[19] Benitez, J. (1993). Process Engineering and Design for Air Pollution Control. (1st ed). PTR Prentice Hall, Englewood Cliffs. Retrieved December 20, 2019, from https: www.amazon.com.

[20] Raso, R. A., M. Zeltner, and W Stark (2014). Indoor air purification using activated carbon adsorbers: Regeneration using catalytic combustion of intermediately stored VOC. Ind. Eng. Chem. Res. 53, 19304-19312.

[21] Khan, F. I. and A. K. Ghoshal, (2000). Removal of volatile organic compounds from polluted air. Journal of Loss Process Industry, 13 (6), 527-545.

[22] Sahle, D. E., and V. G. Devulapelli, (2009). Oxidation of methanol and total reduced sulfur compounds with ozone over $\mathrm{V}_{2} \mathrm{O}_{5} / \mathrm{TiO}_{2}$ Catalyst: Effect of humidity. Applied Catalytic Generation, 361 (1-2), 72-80.

[23] Jiao, Z., P. Luo, Y. Wu, S. Ding, and Z. Zhang, (2006). Absorption of lean formaldehyde from air with $\mathrm{Na}_{2} \mathrm{SO}_{3}$ solution. Journal of Hazardous Materials, 134 (1-3), 176-182.

[24] Nuasaen, S., P. Opaprakasit, and P. Tangboriboonrat (2014). Hollow latex particles functionalized with chitosan for the removal of formaldehyde from indoor air. Carbohydrate Polymer, 101 (1), 179-187.

[25] Quiroz, T. J., S. Royer, J. P. Bellat, J. M. Giraudon, \& J. F. Lamonier (2013). Formaldehyde: Catalytic oxidation as a promising soft way of elimination. Chemistry of sustainability, $6(4), 578-592$.

[26] Chang, M. B., and C. C. Lee (1995). Destruction of Formaldehyde with Dielectric Barrier Discharge Plasmas. Environmental Science and Technology, 29 (1), 181-186.

[27] Plateau State Diary [PSD] (2001). Diary of the State. Published by State Government for 25 th Anniversary of the State. 
[28] Godish, T., W. T. Davis, \& Fu, J. S. (2015). Air Quality, (5th ed.). CRC Press: Boca Raton, FL, USA. ISBN 9781466584440 .

[29] Kurmi, O. P., S. Semple, and M. Steiner (2008). Particulate matter exposure during domestic work in Nepal. Occupational hygiene, 52 (6), 509-17.

[30] Tsai, W. (2010). Toxic volatile organic compounds (VOCs) in the Atmospheric Environment Regulatory Aspects and Monitoring in Japan and Korea. Environments, 3 (3), 23.

[31] Zhu, X., J., Yu, C. Jiang, and B. Cheng (2017). Catalytic decomposition and mechanism of formaldehyde over $\mathrm{Pt}-\mathrm{Al}_{2} \mathrm{O}_{3}$ molecular sieves at room temperature. Physical Chemistry Chemical Physics, 19 (10), 6957-6963.
[32] Toledo-Arana, J., J. J. Torres, D. F. Acevedo, C. O. Illanes, N. A. Ochoa, and C. L. Pagliero (2019). One-Step Synthesis of $\mathrm{CaO}-\mathrm{ZnO}$ Efficient Catalyst for Biodiesel Production. International Journal of Chemical Engineering, 1-7.

[33] Hazra, S., A. K. Kushawaha, D. Yadav, P. Dolui, M. Deb, and A. J. Elias (2019). Table salt as catalyst for oxidation of aromatic alcohols and amines to acids and imines in aqueous medium: Effectively carrying out oxidation reactions in sea water. Green Chemistry. doi: 10.1039/c9gc00497a. 